\title{
¿Fue realmente útil para la sociedad el voto a favor de Vicente Fox?
}

\author{
Juan Manuel Ramírez Sáiz
}

ALBERTO AZIZ Y JORGE ALONSO (coords.), 2005

El Estado mexicano: herencias y cambios. III. Sociedad civil y diversidad: instituciones, actores y movimientos sociales

Centro de Investigaciones y Estudios Superiores en Antropología Social, Miguel Ángel Porrúa, Cámara de Diputados, México.

L os tres libros resultantes de los Utres seminarios realizados por Alberto Aziz y Jorge Alonso sobre el Estado mexicano han originado una notable y muy valiosa producción de conocimientos que son imprescindibles para entender la realidad del poder en México.

El tercer volumen del tercer seminario, El Estado mexicano: herencias y cambios, constituye un sólido y siste- mático análisis sobre las relaciones existentes entre el Estado y los actores más relevantes de la sociedad civil. Este tema estaba ya presente desde el primer seminario sobre el Estado mexicano, celebrado en 1981. En el libro que resultó de ese seminario se decía expresamente que su idea rectora era “dilucidar la relación entre el Estado y la sociedad civil". Entre sus conclusiones relevantes destacaba que entonces

JUAN MANUEL RAMÍREZ SÁIZ: Instituto Tecnológico y de Estudios Superiores de Occidente, Guadalajara, México. jmramire@iteso.mx

Desacatos, núm. 24, mayo-agosto 2007, pp. 308-312.

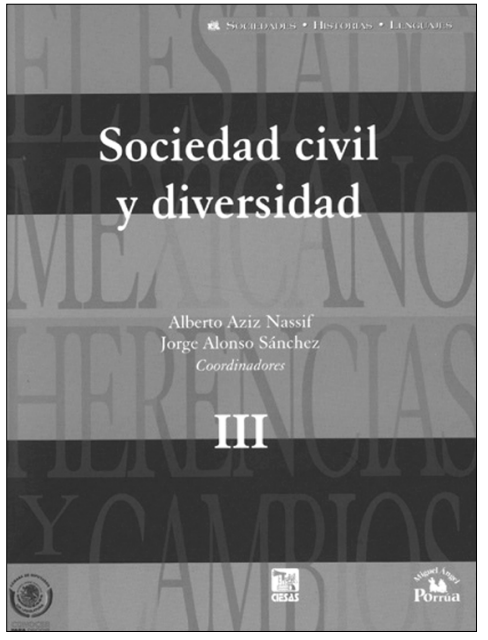

uno de esos actores, "la clase económicamente dominante, realizaba su poder político por medio del Estado". El tema de las relaciones entre el Estado y la sociedad también se abordó en la segunda versión de ese seminario, en 1990. Es notable que en él se resaltara que "se percibía como pujante y desafiante a la sociedad civil".

Si en 2006 hubiera que seleccionar dos referentes para valorar los alcances y limitaciones de los cambios ocurridos, 
habría que reconocer que, a diferencia de 1981, actualmente los empresarios evidencian su poder político no por medio del Estado sino directamente; en contraste con lo que sucedía en 1990, hoy se detecta en la sociedad civil "desencanto e indiferencia ciudadanas crecientes". Un balance final nada optimista.

\section{Actores sociales y temas abordados}

En este volumen se analizan once asuntos: la sociedad mexicana en general, los empresarios, los sindicatos, los medios de comunicación, los movimientos de mujeres en torno a la salud reproductiva, los jóvenes, los grupos conservadores, las políticas indigenistas, el Ejército Zapatista de Liberación Nacional (EZLN), la jerarquía eclesiástica y la cultura política. El eje que cruza la intervención de estos distintos actores y temas es su conexión con el Estado mexicano y las respuestas que éste ha dado a los planteamientos formulados por ellos.

Esta selección de actores y temas representa muy bien la complejidad y diversidad social de México. Era materialmente imposible abordar todos los actores de la sociedad. Aceptando esta premisa, dos actores sociales que considero ausentes en este tercer volumen son: a) los altermundistas mexicanos -en particular, la Red Mexicana de Acción ante el Libre Comercio (RMALC) - , que operan como resistencias y contrapropuestas a la influencia de las fuerzas económicas globalizadas, en particular ante el Tratado de Libre Comercio (TLC) (véanse vol. I, p. 20, y vol. III, p. 399) —en el volumen I se dedican cinco páginas al análisis de varios actores sociales internacionales (Alianza Social Continental, Foro Social Mundial, etc.), pero nada hay sobre los mexicanos-, y b) los dos grupos ciudadanos (Grupo Oaxaca y Colectivo Juan Ciudadano) que fueron los artífices de la propuesta de Ley Federal sobre Transparencia y Acceso a la Información Pública Gubernamental, aprobada en 2002. Esta ley y el Instituto Federal de Acceso a la Información Pública (IFAI) son considerados como la "joya de la corona" del gobierno foxista. Pero la intervención de estos dos grupos fue decisiva, tanto para su elaboración y socialización como para el cabildeo con los diputados y senadores requerido para su aprobación.

\section{El periodo analizado}

En varios de los capítulos de este volumen se consideran algunos antecedentes de la alternancia ocurrida en los poderes federales en el año 2000. Pero la mayoría se centra en el lapso que va de inicios de 2000 a finales de 2003, es decir, en la primera parte de la administración de Fox. Por ello, el resultado final de los trabajos de este volumen arroja un balance de las relaciones que, en esa fase, se dieron entre el gobierno foxista y la sociedad, y que perduran a la fecha.

A continuación, en consonancia con el título general del seminario ("herencias y cambios"), aludo por separado a las innovaciones e inercias que se registran en las relaciones entre ambos. Para comprobarlo, en cada uno de los dos bloques (innovaciones e inercias) resalto brevemente lo más significativo realizado por cada uno de los actores ya referidos.

\section{Lo que ha cambiado}

De acuerdo con el ensayo de Rubén Aguilar, actualmente el control gubernamental sobre las organizaciones sociales es inexistente. Además, las relaciones entre ambos se encuentran ahora más normadas. La innovación principal ha consistido en que se legisló y reglamentó la actividad de las organizaciones civiles. Asimismo, el gobierno federal de alternancia las reconoce como interlocutores, les asigna recursos y establece contacto formal con ellas, principalmente con las de filantropía y desarrollo. También ha impulsado la formación de consejos ciudadanos consultivos y de consejos de participación en las dependencias federales.

En el ensayo de Rafael Montesino se resalta que las cámaras y confederaciones de los empresarios, en cuanto órganos de representación, ya no están estructuradas en torno al corporativismo. Son más plurales y autónomas. Asimismo, los empresarios se han insertado abiertamente en la política. Más aún, ejercen directamente el poder político como diputados, senadores, gobernadores, integrantes del poder federal y como presidente de la República.

Graciela Bensusán recuerda que la reforma electoral de 1996 frenó el poder político de los sindicatos corporativos, al prohibir la afiliación colectiva a los partidos políticos. En una direc- 
ción opuesta, en el gobierno de Vicente Fox, la reforma de la ley laboral registró escasos avances.

Raúl Trejo Delarbre enfatiza que en el viejo régimen autoritario los medios de comunicación se subordinaban a las reglas que marcaba el Estado. Ahora se está consolidando su poder. Se han fortalecido políticamente frente al resto de los actores de la vida nacional. Se imponen a la política y a la sociedad. Esta nueva situación constituye "uno de los rasgos principales —y el más preocupante- entre los que definen las relaciones políticas y la articulación entre la sociedad y el poder" (p. 162). Pero, al mismo tiempo y en otra dirección, actualmente en el país los márgenes de libertad de expresión se han ensanchado y el poder político ha dejado de ser intocable.

Según Dora Cardaci y Ángeles Sánchez Bringas, bajo el régimen de la alternancia política panista era previsible que se ensancharan los espacios de maniobra para los sectores conservadores y se frenaran las demandas feministas frente a la política demográfica $y$, en particular, sobre la salud reproductiva y la fecundidad. Pero el gobierno de Fox no secundó la posición del Congreso de Guanajuato sobre la penalización del aborto ni cedió a las presiones de los activistas de Pro-Vida.

Rosanna Reguillo advierte que las políticas foxistas hacia los jóvenes no han introducido innovaciones para este sector de la población. Incluso significan un repliegue del Estado benefactor y de su responsabilidad social ante ellos. Les garantiza escasa intervención en las políticas dirigidas a su atención.
Juan Luis Sariego señala que la promesa de Fox como candidato de instaurar una nueva relación con los pueblos indígenas, especialmente con el EZLN, terminó en una Ley Federal sobre la Cultura y los Pueblos Indígenas que no incorporó los acuerdos de San Andrés y relegó a las entidades federativas la definición de leyes y políticas específicas. Héctor Díaz Polanco destaca las innovaciones introducidas por el movimiento zapatista. Mediante el recurso a la desobediencia civil creó en 2003 nuevas instancias de autonomía indígena por medio de los "Caracoles" (municipios independientes) y de las Juntas de Buen Gobierno, como gobiernos locales y regionales.

Fernando González y Bernardo Barranco enfatizan cómo la jerarquía de la Iglesia católica constituye un poderoso actor político de facto y que, en contra de lo que se temía socialmente, si varios de los funcionarios federales del gabinete de Fox militaron anteriormente en la ultraderecha, su actuación gubernamental presente está sometida a otras lógicas (p. 271).

Esteban Krotz subraya que - como nuevas y negativas expresiones de la cultura política, en vista de que los cambios electorales no están incidiendo en el mejoramiento de las condiciones materiales de vida — la alternancia conlleva la desilusión de los ciudadanos hacia la política y la desactivación de sus prácticas de intervención.

Estos once elementos introducen innovaciones en las relaciones existentes entre el Estado y los principales actores de la sociedad. Pero las transformaciones logradas son de distintos niveles: a) destacables, como las regis- tradas en la legislación sobre las organizaciones de la sociedad; b) ambivalentes, como las ocurridas en los empresarios, los medios de comunicación, los grupos conservadores y los indígenas; c) casi irrelevantes, como las que se han dado en los sindicatos; y d) negativas, como las relacionadas con las políticas públicas hacia los jóvenes.

Como valoración de conjunto, si hubiera de calificar el proceso de cambio que se está dando de acuerdo con las categorías de Nuria Cunill, habría que considerarlo como un modelo en el que se combinan rasgos del estadocéntrico y de dependencia recíproca con la emergencia de algunos elementos del sociocéntrico. El recelo mutuo y la desconfianza prevalecientes no permiten a ambos operar bajo el modelo de autonomía y complementaridad recíprocas.

Las relaciones predominantes son todavía estadocéntricas porque prevalece la acción gubernamental sobre la societal y la dependencia de la sociedad sobre el reconocimiento de su autonomía. En este modelo híbrido, las organizaciones cuentan con un margen reducido para incidir en la definición de las políticas sociales que se implementan.

Los rasgos del modelo sociocéntrico que emergen son la incipiente capacidad de autoorganización de la sociedad y la existencia de organizaciones voluntarias y autónomas. Algunas de ellas ejercen funciones críticas ante el Estado; llevan a cabo el monitoreo de su actuación. Pero las intervenciones ciudadanas tienen un impacto reducido en las decisiones gubernamentales. No se puede afir- 
mar que se haya logrado la consolidación de la sociedad.

Finalmente, no afloran todavía rasgos del modelo de autonomía recíproca y complementaridad porque el Estado no es fuerte, ya que no dispone del consenso de la sociedad. Por su parte, la fortaleza de la sociedad se basa en la existencia de un espacio público consolidado, así como en la delimitación clara de sus campos de competencia. Ambos asuntos constituyen déficits históricos en el país. Los encuentros complementarios que se dan entre sociedad y gobierno son únicamente puntuales y la concertación entre ambos es limitada.

Con base en otra tipología clásica (corporativismo, neocorporativismo y pluralismo) es válido afirmar también que actualmente las formas de intermediación entre gobierno y sociedad están transitando de predominantemente corporativas a incipientemente neocorporativas y pluralistas. Esto se debe a que el avance del neocorporativismo y del pluralismo sobre el corporativismo es real pero limitado y parcial. Las formas de intermediación son semicorporativas, porque los actores sociales no son ahora creados por el Estado, pero los márgenes de acción del clientelismo y del corporativismo, aunque son menores, no han desaparecido. Además, la pérdida de influencia de las organizaciones corporativas no está siendo compensada por el "empoderamiento" o adquisición de márgenes significativos de acción por parte de las neocorporativas. Por otra parte, la emergencia de rasgos pluralistas es aún reducida. Se da únicamente entre sectores escasos de la población.

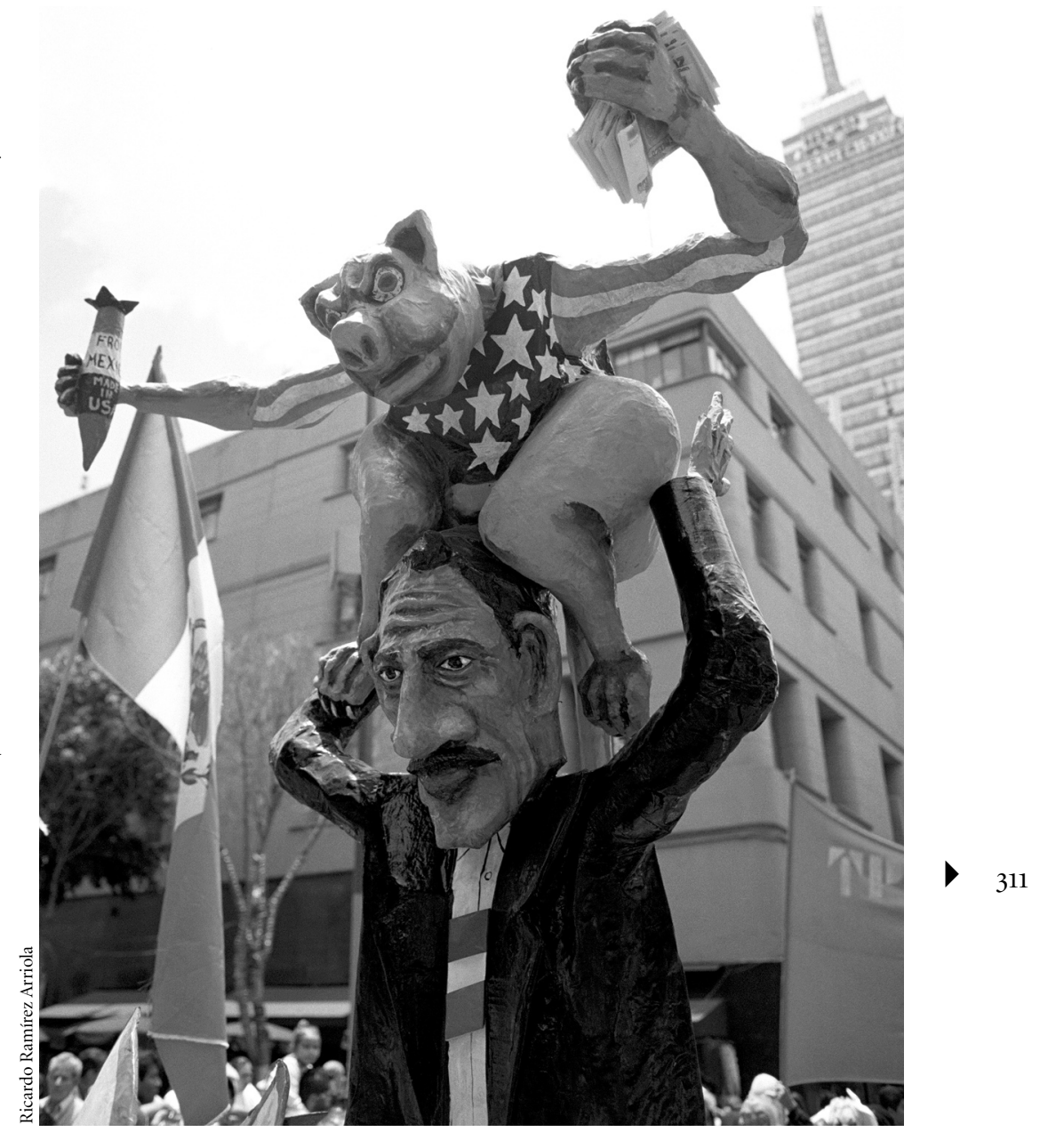

Marcha en contra del desafuero de Andrés Manuel López Obrador, 29 de agosto de 2004.

El saldo final de estos cambios es mucho menos optimista de lo que ofrecía el nuevo gobierno, de lo que realmente posibilitaba la alternancia y de lo que esperaba la sociedad.

\section{Las relaciones que no logró modi- ficar el gobierno de la alternancia}

Frente a los cambios mencionados (positivos, ambivalentes, casi irrele- vantes o negativos) es obligado resaltar los ámbitos en los que se mantienen los viejos esquemas de relación entre Estado y sociedad.

Al diagnóstico de Rubén Aguilar habría que agregar que, entre gobierno y sociedad continúan los recelos y el escaso respeto mutuo. Los nuevos órganos ciudadanos creados avalan frecuentemente las políticas y acciones del Estado. Y las agendas ciudadanas terminan supeditándose 
a la estatal y, en esa medida, burocratizándose.

Con Rafael Montesinos hay que resaltar que ahora los empresarios suman a su poder económico el político que ejercen desde el propio gabinete de $\mathrm{Vi}$ cente Fox. Y está en lo cierto Graciela Bensusán cuando sostiene que la alternancia no tuvo como proyecto cuestionar o frenar el viejo corporativismo sindical. Por el contrario, mantuvo las alianzas con él para preservar la estabilidad económica y política.

Raúl Trejo sostiene que continúa el viejo régimen legal en materia de medios de comunicación. El gobierno de la alternancia se ha mostrado cómplice con los oligopolios televisivos. Ante ellos los partidos actúan como clientes. Por su parte, los ciudadanos están demostrando escasa capacidad de que frenen la fuerza creciente de los medios en la vida pública.

Dora Cardaci y Ángeles Sánchez Bringas recuerdan que, como en el pasado inmediato, los sectores conservadores han buscado revertir los avances logrados en el terreno de los derechos sexuales y reproductivos. Pero también, como en las décadas pasadas, los grupos feministas no cuentan con una posición unificada respecto a los modos de hacer política en este terreno (organización y actuación autónomas o mantenimiento de posiciones filantrópicas y asistencialistas) (p. 191).

De acuerdo con Rosanna Reguillo, el gobierno federal de alternancia considera a los jóvenes como peligrosos, sobre todo a los de sectores urbanos más pobres. Las respuestas estatales a los jóvenes no están basadas en las

garantías ciudadanas. Representan medidas puntuales y con un horizonte de escaso alcance.

Juan Luis Sariego insiste en que son predominantes los elementos de las actuales políticas públicas indígenas que significan continuidad con el pasado. Como en el régimen priísta, no responden a los derechos exigidos por los pueblos indios. Y siguen siendo erráticas. Para Héctor Díaz Polanco, en el EZLN subsiste una relación problemática con los partidos y los procesos electorales, así como con el poder federal y el de Chiapas.

Según Bernardo Barranco, la jerarquía eclesiástica católica, en cuanto actor político, sigue enfrentando fuertes dificultades para establecer relaciones horizontales con los sectores de la sociedad civil: partidos, medios, academia y grupos minoritarios (p. 365). Para Fernando González, una continuidad de signo positivo estriba en el hecho de que, a pesar de la participación de funcionarios conservadores en el gabinete de Vicente Fox, subsiste el Estado laico y el respeto a las libertades fundamentales. Se está evitando el riesgo de que la ultraderecha restaure un orden social cristiano.

Esteban Krotz sostiene que entre los sectores populares las formas principales de participación política siguen siendo el sentimiento de pertenencia local, el involucramiento cotidiano en acciones comunitarias y la cooperación en diversas formas de sociabilidad (p. 384).

Los datos anteriores sobre la continuidad de las viejas relaciones predominantes entre Estado y sociedad arrojan serias dudas acerca de si, para la sociedad, ha merecido la pena la al- ternancia y sobre si el voto a favor de Vicente Fox fue realmente útil.

Por no haberse logrado cambios significativos en el sistema político ni nuevos pactos entre las fuerzas sociales principales, la reforma del Estado queda como otra de las muchas promesas incumplidas de la administración de Vicente Fox. Pero es preciso reconocer que si el Estado no ha sabido ejercer el poder para instaurar los cambios requeridos en las instituciones y en las políticas públicas, tampoco la sociedad (en el periodo foxista) ha encontrado las vías para operar como elemento activo en esa transformación central que está pendiente. Por ejemplo, las organizaciones de la sociedad civil no han tomado posición ni actuado frente a los poderes fácticos como los empresarios, los medios de comunicación y los narcotraficantes que están apoderándose de espacios crecientes de la sociedad. Tampoco se está logrando la convergencia entre los actores sociales (analizados en el libro) para ir logrando la reforma del Estado desde abajo.

En síntesis, los coordinadores y los autores de este volumen han documentado y argumentado sólidamente las ambivalencias prevalecientes en las relaciones que se dan entre Estado y sociedad, así como las oportunidades perdidas por ambos para avanzar en la reforma del Estado. Urgen mejores tiempos políticos y mejores gobernantes. Pero también ciudadanos que hagan un uso más lúcido de su voto y que operen como actores autónomos y complementarios en la construcción de un Estado realmente justo, eficaz y responsable.

marzo de 2006 